\title{
Sistem Keamanan Ruangan Berbasis Arduino Uno R3 Dengan Sensor PIR dan Fingerprint
}

\author{
Adzhal Arwani Mahfudh ${ }^{1}$ Mochammad Ali Ridho Fathoni ${ }^{3}$ Sahrul Ramadhani \\ 1,2,3Program Studi Teknologi Informasi, Fakultas Sains dan Teknologi, Universitas Islam \\ Negeri Walisongo Semarang Indonesia \\ e-mail: ${ }^{1}$ adzhal@walisongo.ac.id, \\ ${ }^{2}$ mochammad_ali_ridho_fathoni_2008096061@walisongo.ac.id \\ ${ }^{3}$ sahrul_ramadhani_2008096029@walisongo.ac.id
}

\begin{abstract}
This security system utilizes micro controller technology in the form of Arduino Uno $R 3$ as a security control center, besides this security technology is equipped with Passive Infra Red (PIR) sensors which are placed in the room and fingerprint as an access access that has been designed to secure goods in the room, This technology is designed to secure objects in a room by limiting access to the room through fingerprint technology as the main opening of the entrance. This security system is built with the concept of logic gates and $C$ and $C++$ programming languages and is equipped with safety technology when there is an electric power problem.
\end{abstract}

Keywords Micro controller, Arduino Uno R3, FingerPrint, PIR

\begin{abstract}
Abstrak
Sistem keamanan ini memanfaatkan teknologi mikro kontroler berupa Arduino Uno R3 sebagai pusat pengendali keamanan, selain itu teknologi keamanan ini dilengkapi dengan sensor Passive Infra Red (PIR) yang diletakkan dalam ruangan serta fingerprint sebagi akses masuk yang telah dirancang untuk mengamankan barang yang ada dalam ruangan, teknologi ini dirancang untuk mengamankan objek dalam ruangan dengan membatasi akses masuk ruangan tersebut melalui teknologi fingerprint sebagai pembuka utama pintu masuk. Sistem keamanan ini dibangun dengan konsep gerbang logika dan bahasa pemrograman $\mathrm{C}$ dan $\mathrm{C}++$ serta di lengkapi dengan teknologi pengaman ketika terjadi permasalahan daya listrik.
\end{abstract}

Kata kunci Mikro kontroler, Arduino Uno R3, FingerPrint, PIR 


\section{PENDAHULUAN}

Perkembangan teknologi saat ini sangat pesat khususnya di bidang komputerisasi dan elektronika. Teknologi yang dikembangkan bertujuan untuk memberikan keamanan, baik keamanan diri maupun keamanan terhadap barang-barang berharga dan dokumen-dokumen penting agar terhindar dari tindak kriminalitas, khususnya tindakan pencurian. Barangbarang dan dokumen-dokumen penting biasanya disimpan dalam suatu ruangan khusus agar tidak diambil oleh orang-orang yang tidak berhak. Menanggulangi hal tersebut, pihak perusahaan maupun instansi harus menambah pengeluaran untuk membuat sistem keamanan yang efektif dan efisien. Proses pengawasan pintu dibantu dengan penerapan teknologi, merupakan salah satu solusi agar efisiensi dan proses pengawasannya lebih terstruktur dan lebih baik. Keamanan sebuah ruangan menjadi faktor penting dalam melakukan pengamanan. Lemahnya sistem keamanan ruangan yang diberikan untuk menjaga barang-barang dan dokumen-dokumen penting tersebut, memberikan peluang dan kesempatan pada orang lain yang tidak berhak mengambil dan mencuri barangbarang tersebut.

\section{METODE}

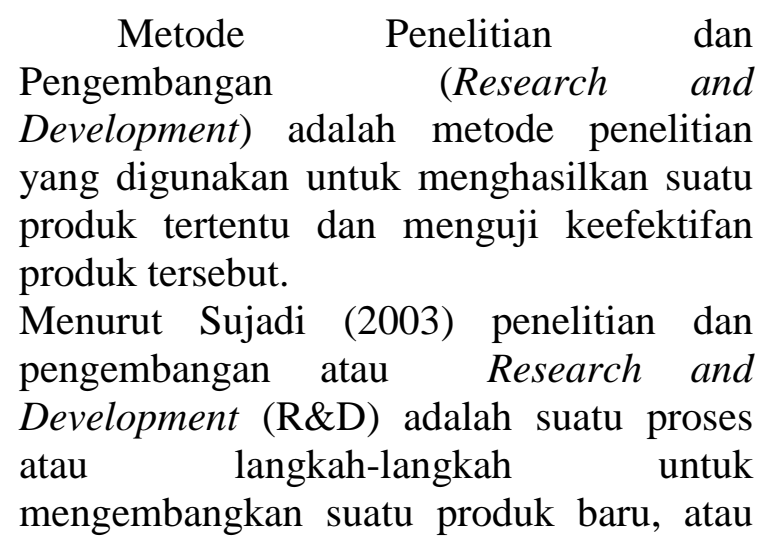

menyempurnakan produk yang telah ada, yang dapat dipertanggungjawabkan.

Dalam metode penelitian dan pengembangan atau $R \& D$, diperlukan beberapa proses, seperti mengembangkan ide-ide, seleksi ide potensial, mengeksplorasi ide potensial, riset pasar, mewujudkan ide, Prototype, uji coba, produk massal, dan pengenalan produk pada masyarakat. Nusa Putra (2011) mengatakan bahwa, Tim Pusat Penelitian dan Inovasi Pendidikan Balitbang Kemendiknas (Tim Puslitjaknov) merangkum penjelasan Borg dan Gall mengenai proses atau tahapan $R$ and $D$ sebagai berikut :

a. Melakukan penelitian pendahuluan (Research and information colleting) untuk mengumpulkan informasi (Kajian pustaka, pengamatan kelas), identifikasi permasalahan yang dijumpai dalam pembelajaran, dan merangkum permasalahan.

b. Melakukan perencanaan (Planning) seperti identifikasi dan definisi keterampilan, perumusan tujuan, penentuan urutan pembelajaran, dan uji ahli atau uji coba pada skala kecil, atau expert judgement.

c. Mengembangkan jenis/bentuk produk awal (development preminary form of product) meliputi: penyiapan materi pembelajaran, penyusunan buku pegangan, dan perangkat evaluasi.

d. Melakukan uji coba lapangan tahap awal (Preliminary field testing), dilakukan terhadap 2-3 sekolah menggunakan 6-10 subjek. Pengumpulan informasi/data dengan menggunakan observasi, wawancara, dan kuesioner, dan dilanjutkan analisis data.

e. Melakukan revisi terhadap produk utama (main product revision), berdasarkan masukan dan saran-saran dari hasil uji lapangan awal. 
f. Melakukan revisi terhadap produk operasional, berdasarkan masukan dan saran-saran hasil uji lapangan.

g. Melakukan uji lapangan operasional, data dikumpulkan melalui wawancara, observasi, dan kuesioner.

h. Melakukan revisi terhadap produk akhir, berdasarkan saran dalam uji coba lapangan.

i. Mendesiminasikan mengimplementasikan dan melaporkan dan menuk, melaporkan dan menyebarluaskan produk melalui pertemuan dan jurnal ilmiah, bekerja bersama dengan penerbit untuk sosialisasi produk untuk komersial, dan memantau distribusi dan kontrol kualitas.

Berdasarkan model pengembangan yang dilakukan menggunakan model research and developmen (R\&D) Borg dan Gall, prosedur pengembangan yang ditempuh terdiri dari enam langkah, yaitu (1) Research and information colleting (2) Planning (3) development preminary form of product (4) Preliminary field testing (5) main product revision (6) Main field testing. Maka prosedur pengembangan dalam penelitian pengembangan ini mengikuti langkah yang di instruksikan dalam model desain tersebut.

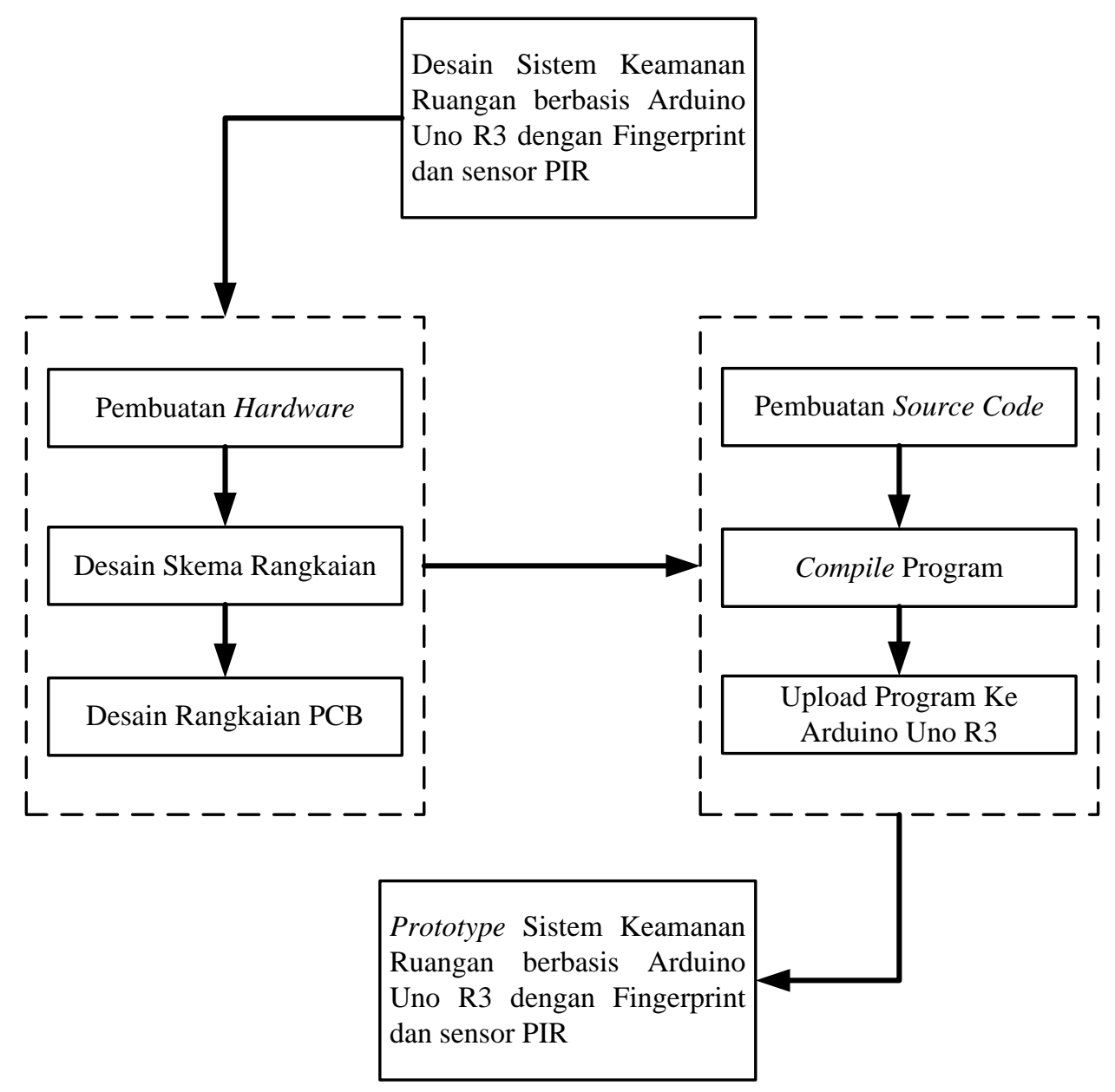

Gambar 1. instruksikan dalam model desain 
Langkah-langkah diatas dijelaskan sebagai berikut :

1. Analisa kebutuhan

Dalam langkah ini antara lain :

a. Studi Literatur

Penulis melakukan studi literatur yang berkaitan dengan permasalahan yang dikaji untuk menemukan konsep-konsep atau landasan-landasan teoritis yang memperkuat produk yang akan dihasilkan dan memaparkan teoriteori tersebut, antara lain mengenai sistem, keamanan, sistem keamanan ruangan, Arduino Uno R3, sensor PIR, Selenoid Door Lock, penelitian dan pengembangan (R\&D). Studi literatur ini didapatkan melalui sumber-sumber antara lain buku, jurnal, hasil karya penelitian orang lain dan dari internet.

b. Penelitia Dalam Skala Kecil

Melalui penelitian dalam skala kecil ini penulis mengumpulkan informasi melalui observasi dan wawancara untuk mendapatkan informasi dan data-data yang terkait dengan kondisi keamanan lingkungan dan keamanan ruangan.

2. Pembuatan rancangan produk

Dalam tahap ini dimulai dengan perencananaan spesifikasi produk yang dikembankan melalui perumusan tujuan dari penggunaan produk yang dibutuhkan oleh user, yaitu membuat perancangan sistem keamanan ruangan yang berbasis Mikrokontroler menggunakan teknologi Arduino Uno R3, Fingerprint dan sensor PIR yang valid. Melalui penetapan spesifikasi produk yang dikembangkan maka dapat diperoleh gambaran mengenai produk yang dikembangkan yang selanjutnya dapat dibuat rancangan sistem keamanan baru berdasarkan penilaian terhadap sistem keamanan lama, sehingga dapat ditemukan kelemahan-kelemahan terhadap sistem lama tersebut dan kemudian dikembangkan menjadi sistem yang baru. Pengembangan produk dilakukan dengan membuat perancangan sistem keamanan meliputi schematic desain, Desain Rangkaian PCB, flowchart dan percobaan.

3. Uji validasi desain

Melakukan uji coba lapangan awal dalam skala terbatas, dengan melibatkan subjek secukupnya dalam hal ini pakar yang diwakili oleh dosen yang berekompeten di bidangnya. Pada langkah ini dilakukan pengujian dan validasi dsain sistem berupa pengujian schematic desain, desain rangkaian PCB, flowchart dan percobaan apakah desain sudah valid atau belum. Validasi desain dilakukan dengan menggunakan instrumen penelitian yaitu instrumen validasi pakar berupa form validasi pakar.

4. Revisi produk awal

Bedasarkan hasil uji validasi pakar jika terdapat kesalahan atau ketidak tepatan dalam perancangan sistemnya dilakukan perbaikan terhadap desain produk awal atau dalam hal ini berupa schematic desain, desain rangkaian PCB, flowchart dan percobaan prototype. Perbaikan ini sangat mungkin dilakukan lebih dari satu kali, sesuai dengan hasil yang ditunjukkan dalam uji coba terbatas, sehingga diperoleh draft produk (model) utama yang siap dikembangkan menjadi sebuah produk prototype sistem keamanan ruangan.

5. Pembuatan sistem kemanan

Setelah desain sitem dinyatakan valid oleh validator maka dilakukan pembuatan produk akhir dengan 
Adzhal Arwani Mahfudh, Mochammad Ali Ridho Fathoni, Sahrul Ramadhani

membuat source code program menggunakan bahasa pemrograman $\mathrm{C}$ menggunakan software IDE arduino dan dibarengi dengan pembuatan hardware kemudian program di download ke dalam arduino uno r3 board. Hasil akhirnya berupa prototipe sistem keamanan studio radio berbasis arduino uno r3 dengan menggunakan fingerprint dan sensor PIR yang sudah berfungsi dan siap dilakukan uji coba

6. Uji coba prototype sistem kemanan Studio

Uji coba utama melibatkan calon user. Dalam tahap ini dilakukan uji coba produk sampai dinyatakan berfungsi dengan baik oleh calon user. Kemudian melakukan revisi produk akhir (sesuai dengan saransaran dari hasil uji coba lapangan oleh user)

\section{HASIL DAN PEMBAHASAN}

Blok diagram rangkaian Sistem Keamanan Studio Radio Berbasis Arduino Uno R3 Menggunakan Fingerprint dan Sensor PIR (Passive Infra Red) salah satu bagian terpenting dalam perancangan suatu alat, karena dari blok diagram rangkaian inilah dapat diketahui cara kerja rangkaian keseluruhan. Sehingga keseluruhan blok diagram rangkaian tersebut akan menghasilkan suatu sistem yang dapat difungsikan atau dapat bekerja sesui dengan perancangan.

Adapun diagram blok rangkaian dari Sistem Keamanan Studio Radio Berbasis Arduino Uno r3 Menggunakan Fingerprint dan Sensor PIR (Passive Infra Red) dapat dilihat pada Gambar dibawah ini.

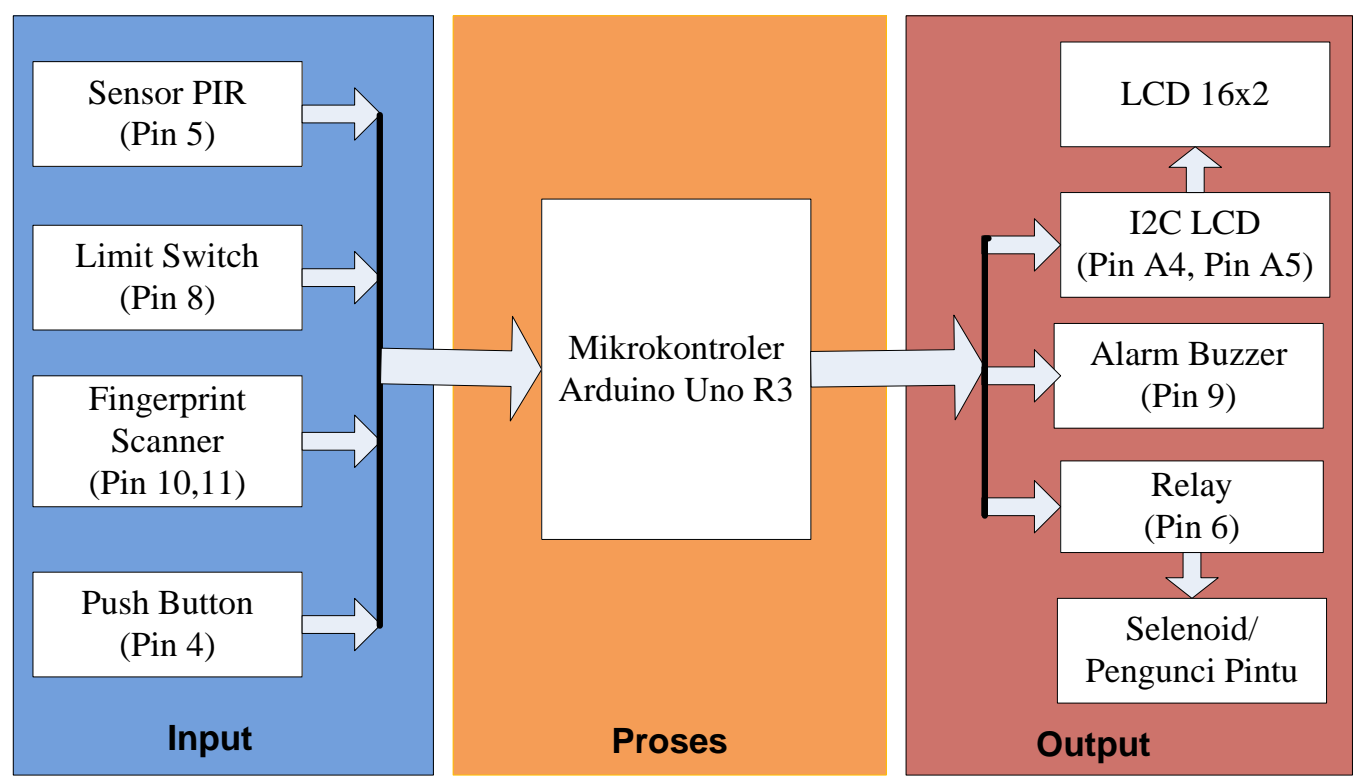

Gambar 2. Blok Diagram Rangkaian 
Dari blok diagram diatas dapat diketahui bahwa konfigurasi dari sistem keamanan ini terdiri dari input, proses dan output. Dari sisi masukan (input) terdiri dari sensor PIR melaluin input digital pin 5 , Limit Switch pada pin 8 dan fingerprint scanner pada input digital pin 10 dan 11 serta push button yang berfungsi membuka pintu dari dalam ruang studio, kontroler yang digunakan adalah Arduino Uno R3, sedangkan dari sisi keluara (output) terdapat relay untuk membuka kunci pintu / Selenoid Door Lock, adapun penggunaan relay pada sistem keamanan ini adalah sebagai jembatan penghubung antara output pin digital 6 dari arduino uno R3 dengan nilai keluaran daya $5 \mathrm{v}$ yang menghubungkan daya $12 \mathrm{v}$ dari adaptor untuk membuka tuas selenoid door lock pada pintu ruangan. Selain itu buzzer dalam sistem keamanan ini berfungsi sebagai alarm apabila ada penyusup masuk tanpa melewati pintu dengan mengakses fingerprint scanner atau dengan cara membobol pintu ruangan, selanjutnya tampilan LCD 16x2 sebagai sistem informasi keamanan yang memberikan informasi kepada pengguna sistem keamanan ini.

Pada dasarnya konsep pembuatan sistem keamanan ini menggunakan kombinasi antara variabel memori yang dibuat pada sketch arduino dalam menentukan kapan sensor PIR aktif dan tidak aktif dalam kondisi Kunci pintu tertutup. Berikut ini adalah ringkasan kombinasi antar variabel dalam menentukan kemungkinan yang akan terjadi pada sistem keamanan ruangan.

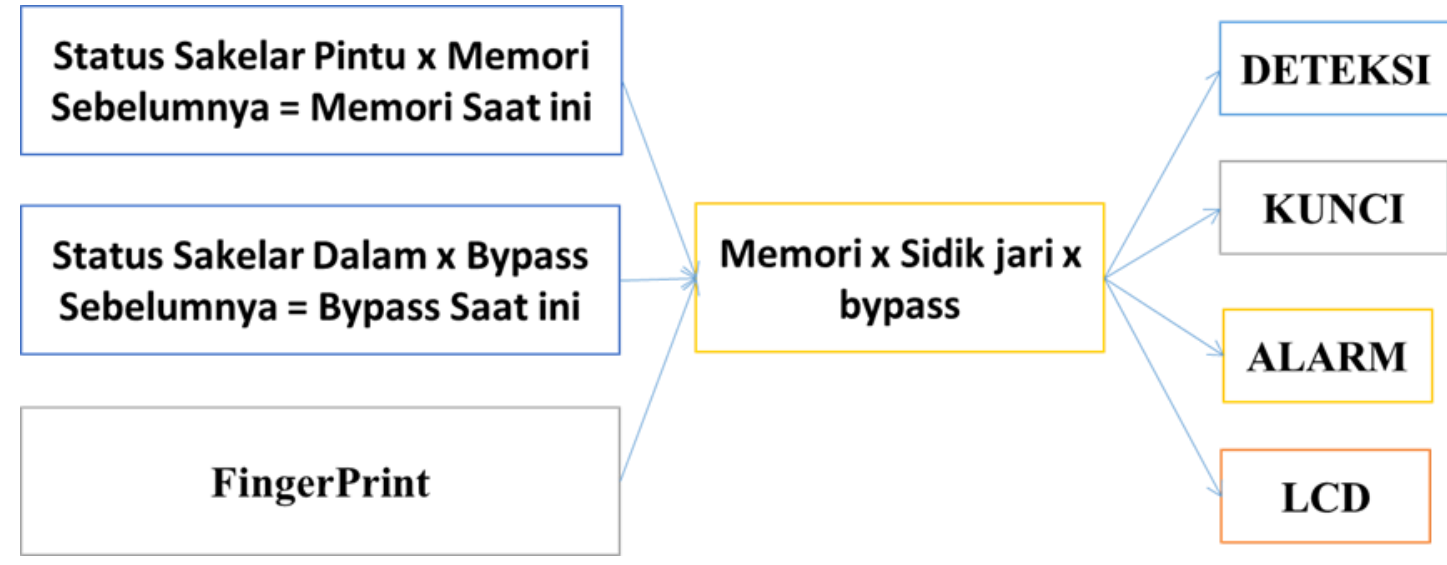

Gambar 3 Konsep Dasar Kombinasi Antar Variabel

Sebelum melakukan koding pada sketch arduino, perlu adanya pemetaan variabel yang akan digunakan termasuk membuat memori sebelum sistem keamanan digunakan dan pada saat memori sedang digunakan yang nantinya akan digabungkan dengan variabel sesuai kondisi yang diinginkan. Berikut ini adalah ringkasan kombinasi antar variabel dalam menentukan variabel memori sebelum dan saat sistem sedang bekerja.

Tabel 1. Penentuan Nilai Variabel "Memori"

\begin{tabular}{|c|c|c|}
\hline Status Sakelar Pintu & $\begin{array}{c}\text { Nilai Variabel "MEMORI" } \\
\text { Sebelumnya }\end{array}$ & $\begin{array}{c}\text { Nilai Variabel "MEMORI" } \\
\text { Saat Ini }\end{array}$ \\
\hline HIGH (PINTU DIBUKA) & $\begin{array}{c}0 \text { (belum dibuka sejak sistem } \\
\text { aktif) }\end{array}$ & 1 (pintu dibuka SEKALI) \\
\hline HIGH (PINTU DIBUKA) & 1 (pintu dibuka SEKALI) & 1 (masih terbuka) \\
\hline LOW (PINTU DITUTUP) & 1 (pintu dibuka SEKALI) & 2 (pintu ditutup SEKALI) \\
\hline
\end{tabular}


Adzhal Arwani Mahfudh, Mochammad Ali Ridho Fathoni, Sahrul Ramadhani

\begin{tabular}{|c|c|c|}
\hline HIGH (PINTU DIBUKA) & 2 (pintu ditutup SEKALI) & $\begin{array}{c}3 \text { (pintu dibuka KEDUA } \\
\text { KALINYA) }\end{array}$ \\
\hline LOW (PINTU DITUTUP) & $\begin{array}{c}3 \text { (pintu dibuka KEDUA } \\
\text { KALINYA) }\end{array}$ & 40 (pintu ditutup kedua kalinya) \\
\hline
\end{tabular}

Setelah memori sebelum dan saat sistem sedang bekerja telah dibuat maka dibutuhkan pula nilai variabel "bypass" untuk membuka pintu dan mereset sistem keamanan setelah user keluar dari ruangan. Berikut ini adalah ringkasan kombinasi antar variabel dalam menentukan variabel "bypass sebelum" dan "bypass saat ini"

Tabel 2. Penentuan Nilai Variabel "Bypass"

\begin{tabular}{|l|l|l|}
\hline \multicolumn{1}{|c|}{ Status Sakelar Dalam } & \multicolumn{1}{c|}{$\begin{array}{c}\text { Nilai Variabel "BYPASS" } \\
\text { Sebelumnya }\end{array}$} & \multicolumn{1}{c|}{$\begin{array}{c}\text { Nilai Variabel "BYPASS" } \\
\text { Saat Ini }\end{array}$} \\
\hline LOW (Sakelar DITEKAN) & $\begin{array}{l}\text { 0 (belum ditekan sejak sistem } \\
\text { aktif) }\end{array}$ & 1 (tombol sedang ditekan) \\
\hline LOW (Sakelar DITEKAN) & 1 (tombol sedang ditekan) & 1 (masih ditekan) \\
\hline $\begin{array}{l}\text { HIGH (Sakelar TIDAK } \\
\text { DITEKAN) }\end{array}$ & $\begin{array}{l}\text { 0 (belum ditekan sejak sistem } \\
\text { aktif) }\end{array}$ & $\begin{array}{l}\text { 0 (belum ditekan sejak sistem } \\
\text { aktif) }\end{array}$ \\
\hline $\begin{array}{l}\text { HIGH (Sakelar TIDAK } \\
\text { DITEKAN) }\end{array}$ & 1 (tombol sedang ditekan) & $\begin{array}{l}\text { 2(tombol dilepas setelah } \\
\text { ditekan) }\end{array}$ \\
\hline
\end{tabular}

Setelah pemetaan kombinasi variabel memori dibuat maka penggabungan dari seluruh variabel akan menghasilkan beberapa kondisi yang akan melengkapi keseluruhan kombinasi pada sketch yang akan diterapkan pada sistem keamanan Studio Radio Aska FM. Adapun kombinasi keseluruhan dari kemungkinan kondisikondisi yang akan ditetapkan adalah seperti pada tabel 3.

Dari hasil pemetaan variabel dan kombinasi antar memori (Tabel Penentuan
Nilai Variabel "Bypass", Tabel Penentuan Nilai Variabel "Memori" dan Tabel Penentuan Status "Deteksi" Dan "Kunci" ), maka dapat diperoleh keseluruhan alur koding pada sketch sesuai dengan perencanaan dan kemungkinan yang telah ditetapkan pada tabel diatas yang akan membatu pada pembuatan dan penentuan logika di dalam sketch arduino. Sehingga diperoleh gambaran pembuatan koding sketch pada arduino secara lengkap adalah sebagai berikut. 


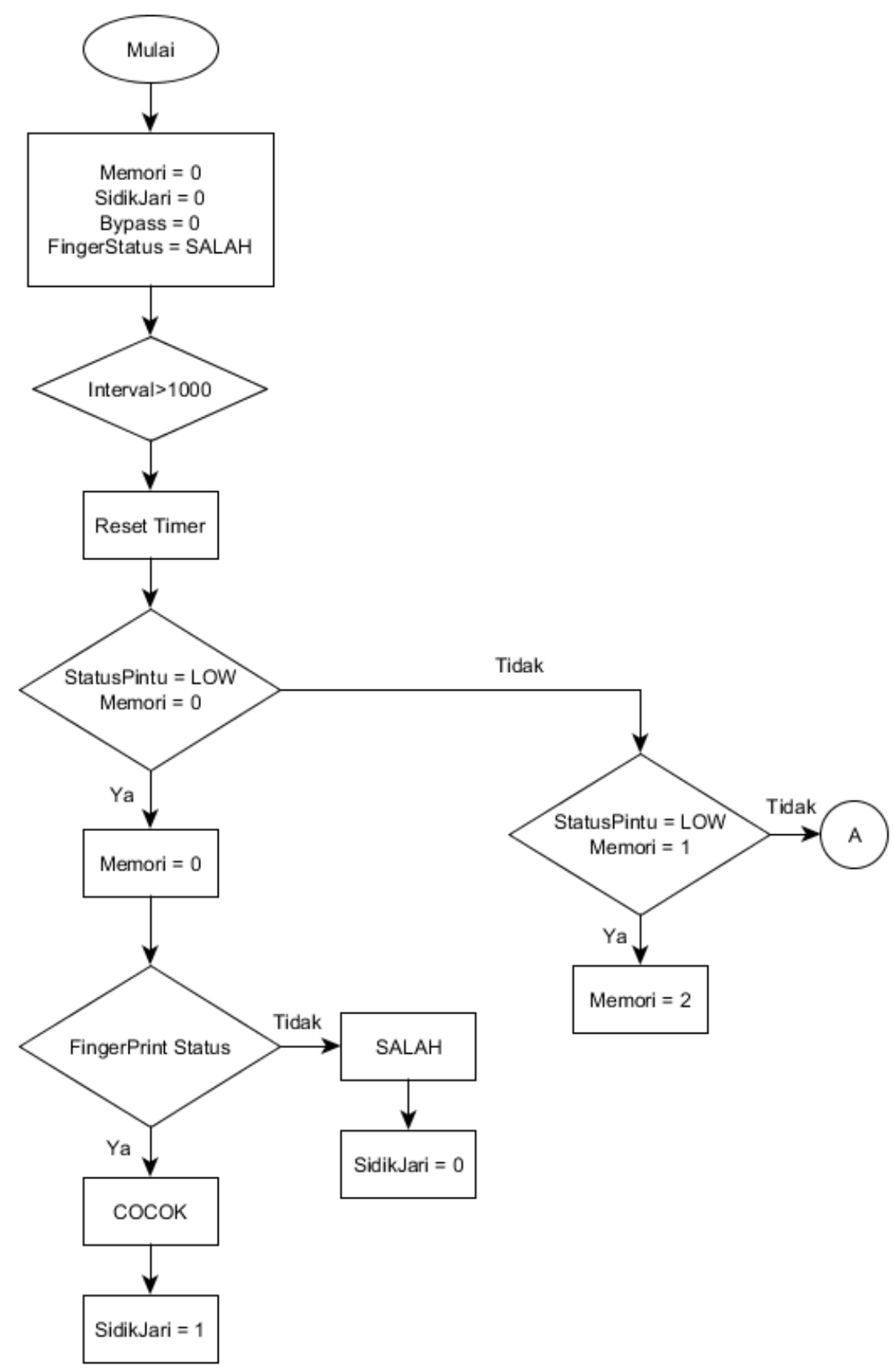

Flowchart Alur Kode Pada Skech Arduino 
Adzhal Arwani Mahfudh, Mochammad Ali Ridho Fathoni, Sahrul Ramadhani

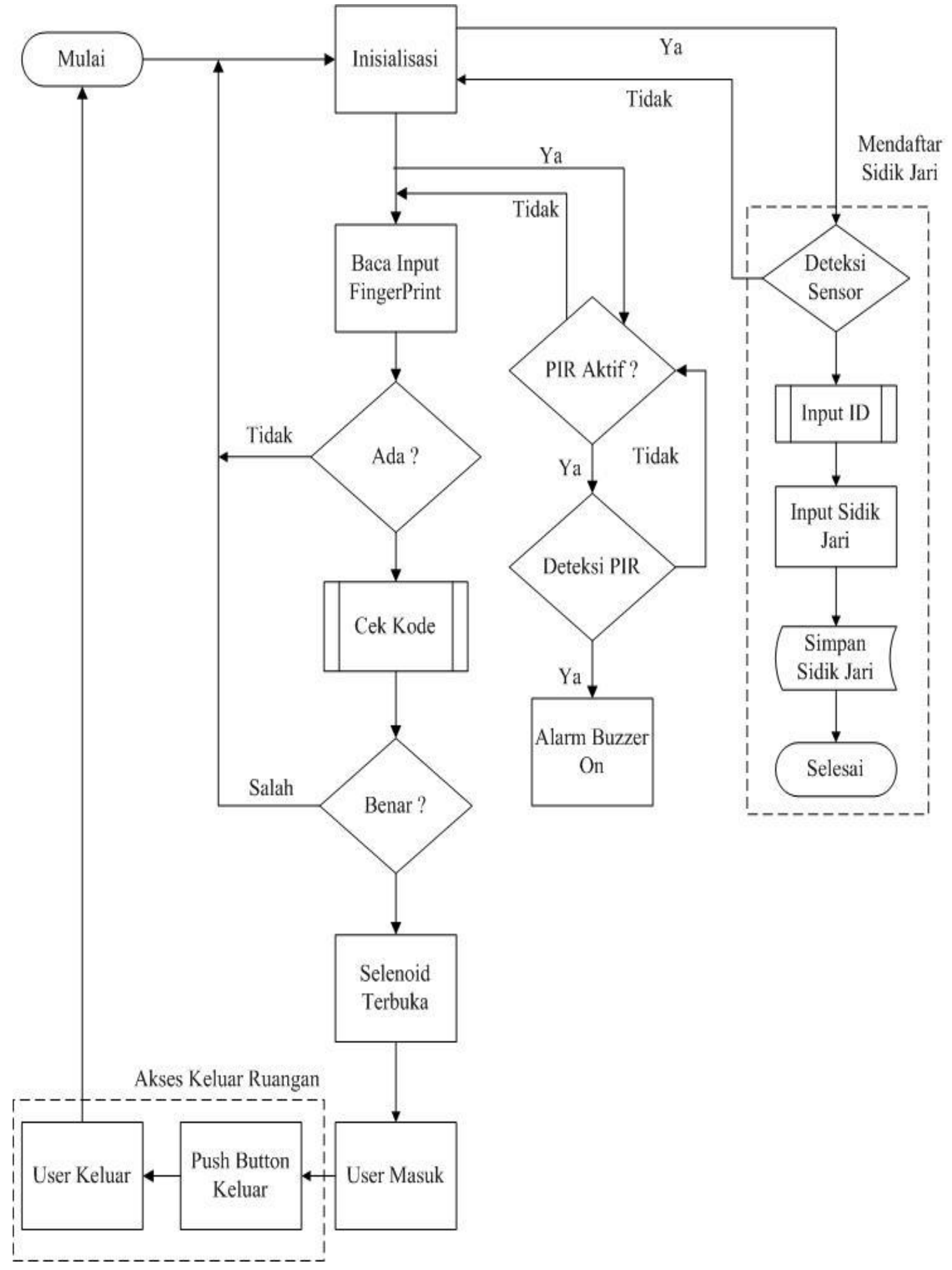

Flowchart Sistem Keamanan Ruangan Berbasis Arduino Uno R3 Menggunakan Fingerprint dan Sensor PIR

WJIT_:_Walisongo Journal of Information Technology - Vol. 3, No. 2 (2021) 
Prinsip dasar alat ini adalah pengendali akses pada pintu secara elekronik menggunakan teknologi fingerprint sebagai pengendali pintu dan dilengkapi dengan sensor PIR jika ada penyusup atau pencuri masuk maka alarm akan berbunyi. Selain itu alat ini juga mampu memberi kenyamanan kepada para user saat meggunakan ruangan.

Dari flowchart tersebut dapat dijelaskan bahwa langkah alat ini adalah mendeteksi adanya sidik jari jika ada maka fingerprint scanner akan membaca sidik jari tersebut jika terdaftar maka aktifkan selenoid dan kunci akan terbuka. Jika sidik jari tidak terdaftar makan kunci akan tetap tertutup dan meminta sidik jari kembali. Jika sensor PIR diaktifkan, alarm penyusup akan aktif apabila ada penyusup alarm akan berbunyi. Selain itu pendaftaran sidik jari juga dimungkinkan atas persetujuan pengelola ruangan apabila sewaktu-waktu ada pergantian atau penambahan pengguna ruangan tersebut. Dibawah ini merupakan prototype rangkaian sistem secara keseluruhan.

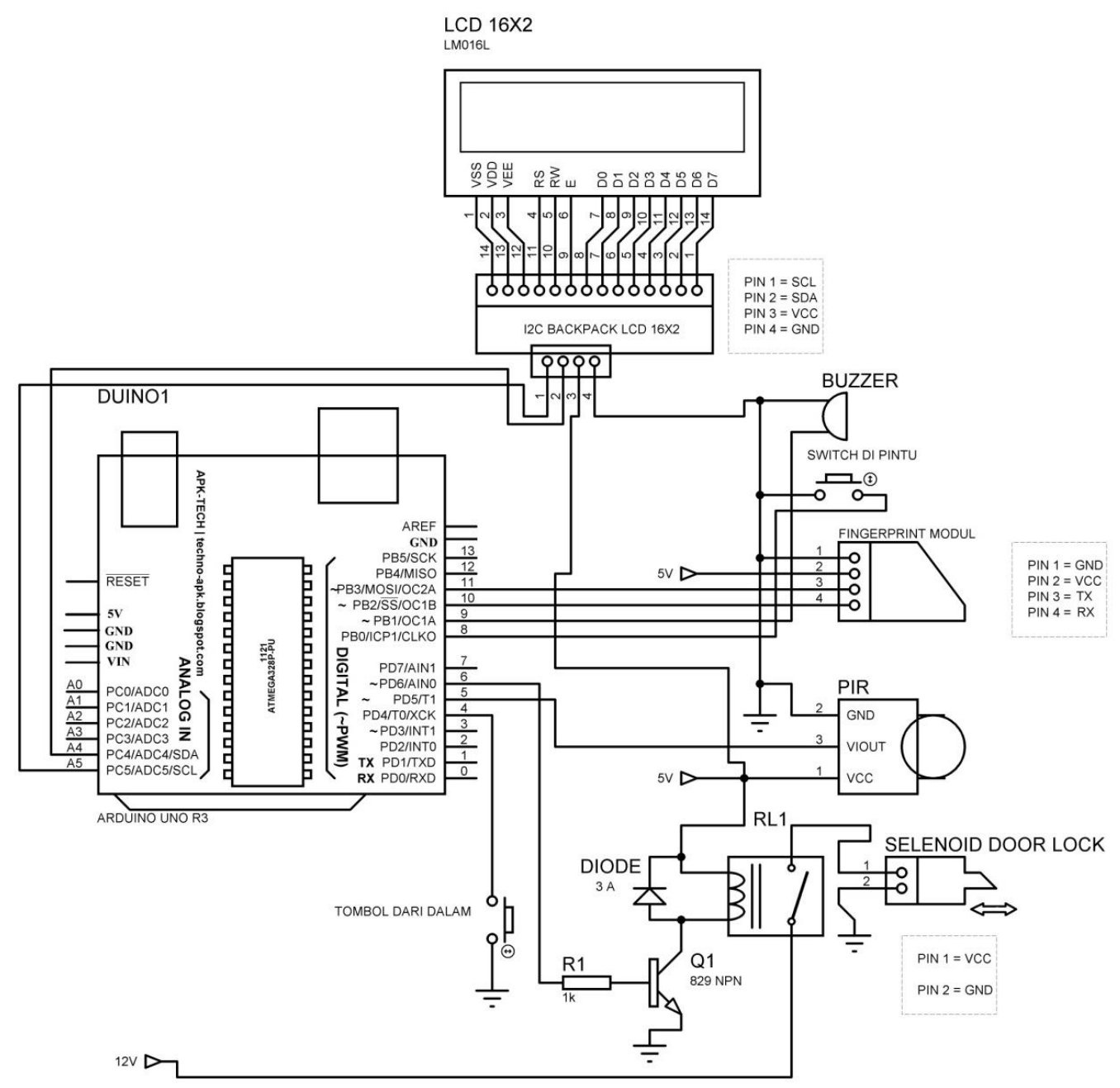

Gambar 3. Rangkaian Skema Sistem Keamanan Ruangan Berbasis Arduino Uno R3 Menggunakan Fingerprint dan Sensor PIR 


\section{KESIMPULAN}

Berdasarkan hasil analisis data pada pengembangan produk sistem keamanan ruangan yang telah di lakukan dengan menggunakan metode Research And Development (R\&D), bahwa kerja sistem lama yang menggunakan kunci biasa memiliki banyak kelemahan untuk mengamankan ruangan, karena pelaku tindak kejahatan mudah untuk membobol pintu ruangan.

Setelah dibangun sistem baru yang telah melalui pengujian desain dan juga ujicoba prototipe oleh user, prototipe sistem keamanan ruangan yang telah dikembangkan dinyatakan layak untuk dikembangkan lebih lanjut menjadi aplikasi yang sebenarnya, karena telah memenuhi beberapa kebutuhan pengamanan ruangan, sebagai berikut :

1. Mampu melakukan pengamanan dari tindak kejahatan pencurian seperti dengan cara membobol pintu ruangan, karena apabila pintu dibuka secarapaksa, maka limit switch pada kusen pintu akan merespon sehingga alarm berbunyi.

2. Dapat memberikan kenyamanan pada user saat berada dalam ruangan, karena sistem ini akan secara otomatis membatasi akses masuk pengguna ruangan ketika ruangan sedang dimanfaatkan.

3. Lebih aman dalam mengamankan pintu ruangan menggunakan fingerprint yang memiliki keunggulan sifat tidak dapat dilupakan, ditiru, atau dipindah tangankan.

4. Mampu melakukan pengamanan apabila ada pelaku tindak kejahatan dengan cara menyusup melalu jendela atau celah ventilasi, sesor PIR akan mendeteksi penyusup dan alarm akan berbunyi

5. Sistem keamanan ini, akan membatasi siapa saja yang dapat atau diperbolehkan masuk ke dalam ruangan berdasarkan data sidik jari yang sudah disimpan sebelumnya.

6. Sistem keamanan ini dilengkapi dengan tombol emergency ketika terjadi kerusakan pada UPS (Uninterruptible Power Supply) atau pemadaman listrik, user dapat mengaktifkan kontrol emergency yang akan membuka pintu secara otomatis melalui daya baterai. 


\section{REFERENCE}

Arduino Home Page. (2014). Arduino Uno [Online]. Tersedia : http://www.arduino.cc/en/Main/ArduinoBoardUno

Dony Saputra, Abdul Haris Masud, Muhammad Ramadhan, Dian Fitriani. 2014. Akses Kontrol Ruangan Menggunakan Sensor Sidik Jari Berbasis Mikrokontroler Atmega328P. Yogyakarta : Seminar Nasional Teknologi Informasi dan Komunikasi (SENTIKA).

Erlina Cahya Setianingrum, Bambang Eka Purnama. 2013. Sistem Pengaman Brankas Dengan Menggunakan Handphone Berbasis Mikrokontroler At89s51. Surakarta : Universitas Surakarta.

Fried, Limor. 2005. Fingerprint Sensor. [online]. Tersedia : http://www.Learn.adafruit.com/adafruit-optical-fingerprint-sensor/wiring-for-use-witharduino.

Helmi Guntoro, Yoyo Sumantri, Erik Haritman. 2013. Rancang Bangun Magnetic Door Lock Menggunakan Keypad dan Selenoid Berbasis Mikrokontroler Arduino Uno. Bandung : Electrans.

Jogiyanto. 2005. Analisis dan Desain Sistem Informasi: Pendekatan Terstruktur Teori dan Praktek Aplikasi Bisnis. Yogyakarta : Andi

Joyner R. Oroh, Elia Kendekallo, Sherwin R. U. A. Sompie, Janny O. Wuwung. 2014. Rancang Bangun Sistem Keamanan Motor Dengan Pengenalan Sidik Jari. Manado : UNSRAT.

Kadir, Abdul. 2015. Buku Pintar Pemrograman Arduino. Yogyakarta : Mediakom.

Kelas Mikrokontrol. (2015). Bahasa pemrogramanArduino. [Online]. Tersedia : http://www.kelas-mikrokontrol.com/e-learning/mikrokontoler/bahasa-pemrogramanarduino.html

Kelas Mikrokontrol. (2014). Arduino. [Online]. Tersedia : http://www.kelasmikrokontrol.com/e-learning/mikrokontoler/pengantar-arduino.html

Limit Switch dan Saklar Push On. (2015). http://elektronika-dasar.web.id/komponen/limitswitch-dan-saklar-push-on

Modul Fingerprint FPM10 FPM10A. (2015). Elektronika Dasar. indo-ware.com/produk3580-modul-sensor-sidik-jari-finger-print-fingerprint-fpm10-fpm10a.html $\quad\left[\begin{array}{ll}20 & \text { Mei }\end{array}\right.$ 2015].

Melalolin, Ivan C. 2013. Rancang Bangun Brankas Pengaman Otomatis Berbasis Mikrokontroler At89s52. Bandung : Universitas Komputer Indonesia.

Sugiyono. 2011. Metode Penelitian Kuantitatif Kualitatif dan R\&D. Bandung : Alfabeta

Syahwil, muhammad. 2013. Panduan Mudah Simulasi Dan Praktek Mikrokontroler Arduino. Yogyakarta: Andi. 